\title{
Spontaneous regression of sequestrated and extruded lumbar disc herniation
}

\author{
Hakan Yılmaz, ${ }^{1}$ Ufuk Kuş̧uoğlu, ${ }^{1}$ Ümit Kocaman ${ }^{2}$ \\ 'Department of Neurosurgery, Ușak University Training and Research Hospital, Ușak, Turkey \\ ${ }^{2}$ Department of Neurosurgery, İzmir Çiğli Training and Research Hospital, İzmir, Turkey
}

Received: February 2017 Accepted: April 2017

We have read with great interest the article on resorption of sequestrated lumbar disc herniation with conventional therapy by Cizmeci et al. ${ }^{[1]}$ We would like to share our experiences on similar cases. Although patients of spontaneous regression between six months and one year were reported in the literature, the patients with resorption of the sequestered fragment in a short period of two months is rather rare in the literature. ${ }^{[2,3]}$ We would like to present our two patients with resorption of the sequestered fragment in a short period of two to three months.

A 37-year-old female patient was admitted to our hospital with a lumbago for four months and left leg pain which exacerbated for two weeks. On the neurological examination, the left leg stretch test was positive at $45^{\circ}$ and deep tendon reflexes were normal. She had no neurological deficit and there were no findings for cauda equina syndrome. There was hypoesthesia in the region corresponding to the L5 dermatome on the left lower extremity. Lumbar magnetic resonance imaging (MRI) of the patient revealed a sequestrated disc at the L4-5 level (Figure 1a). The patient was offered surgery, but she did not accept. At two months during follow-up, pain was reportedly relieved by medical treatment and resting. The patient did not receive physical therapy; she had bed rest and used analgesics and anti-inflammatory drugs for two months. On her neurological examination the Lasegue test was negative, and motor and sensory deficit was absent. Repeated lumbar MRI was done due to incompatibility of previous imaging with clinical examination. It was seen that the sequestered fragment was completely regressed in the repeated MRI (Figure 1b).
The other case was a 65-year-old female patient who was admitted to our hospital with lumbago for three weeks and left leg pain. On neurological examination, the left leg stretch test was positive at $60^{\circ}$. She had no neurological deficit and there were no findings for
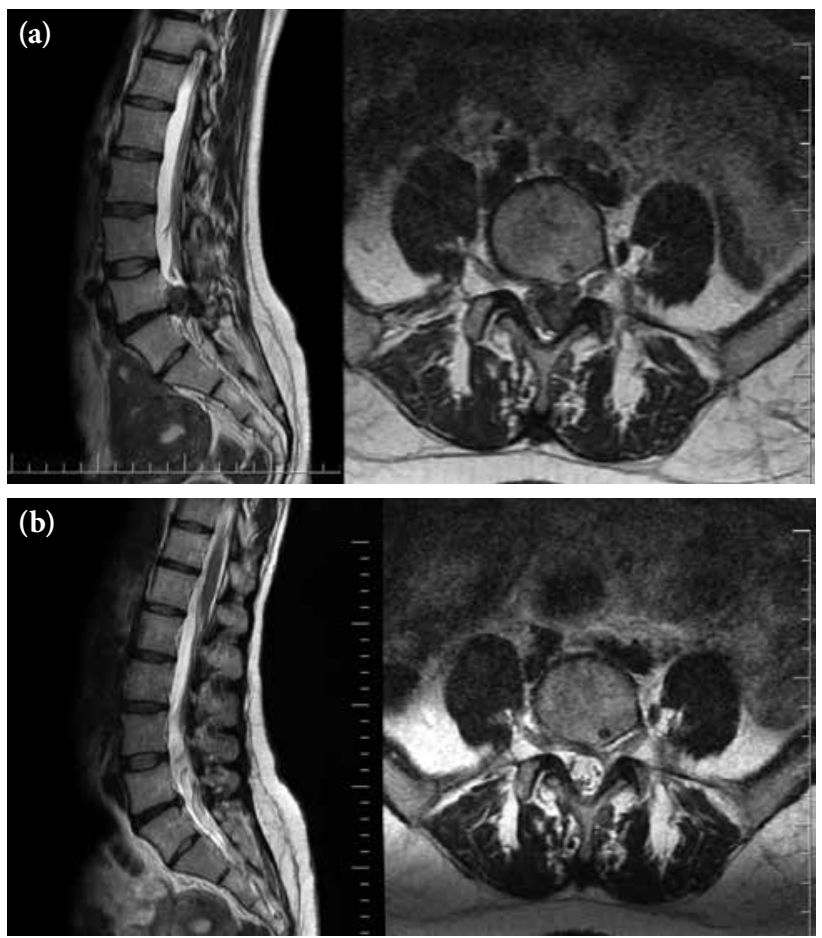

Figure 1. (a) A sagittal and axial $\mathrm{T}_{2}$-weighted image of the initial magnetic resonance imaging study showing a left-side large sequestrated disc at the L4/5 level. (b) Two months later, repeated magnetic resonance imaging showing almost complete regression of sequestrated disc at the L4/5 level.

Corresponding author: Hakan Yılmaz, MD. Uşak Üniversitesi Tip Fakültesi Eğitim ve Araştırma Hastanesi, Nöroşirürji Anabilim Dall, 64300 Uşak, Turkey. e-mail: dr_hakanyilmaz@hotmail.com 

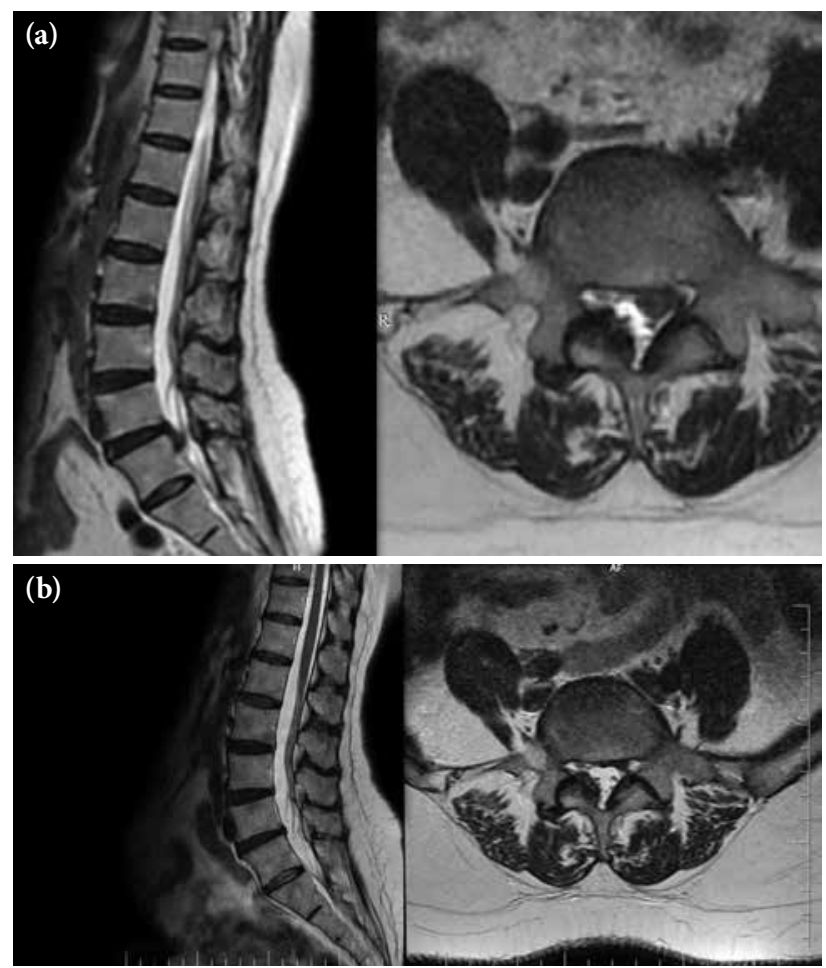

Figure 2. (a) $\mathrm{A}$ sagittal and axial $\mathrm{T}_{2}$-weighted image of the initial magnetic resonance imaging study showing a left-side extruded disc at the L4/5 level. (b) Three months later, repeated magnetic resonance imaging showing almost complete regression of extruded disc at the L4/5 level.

cauda equina syndrome. Her lumbar MRI revealed extruded disc at the L4-5 level (Figure 2a). The patient was offered surgery, but she did not accept. At three months during follow-up, her complaint decreased with physical therapy. She received three physical therapy sessions within three months. Transcutaneous electrical nerve stimulation (TENS) and cryotherapy were also applied for $20 \mathrm{~min}$ in these sessions. She had normal neurological examination findings. Repeated lumbar MRI was done due to incompatibility of previous imaging with clinical examination. It was seen that the extruded fragment was regressed in the repeated MRI (Figure $2 b$ ).

Spontaneous regression time is not clear. In cases of spontaneous regression, it has been reported that the regression usually occurs between six months and one year. In the published case reports, regression was often accompanied by clinical improvement. ${ }^{[1,4-6]}$ In our cases, sequestrated and extruded fragments were almost completely resolved in a short time such as two months.

Cizmeci et al. ${ }^{[1]}$ presented a case of spontaneous regression of a sequestrated disc herniation in a patient with motor deficit and urinary incontinence. Motor deficit and urinary incontinence were not present in our cases. It is clear that surgery is the first choice, when severe pain, despite medical treatment, progressive neurological deficit, and cauda equina syndrome are present in patients with extruded and sequestrated lumbar disc herniation. In the absence of these symptoms, we should not be hasty and persistent on the operation. In conclusion, according to the preferences of the patient, well-planned physical therapy modalities and bed rest may be useful for patients with major lumbar disc herniation.

\section{Declaration of conflicting interests}

The authors declared no conflicts of interest with respect to the authorship and/or publication of this article.

\section{Funding}

The authors received no financial support for the research and/or authorship of this article.

\section{REFERENCES}

1. Cizmeci HO, Soysal M, Tur BS. Resorption of sequestrated lumbar disc herniation with conventional theraphy. Turk J Phys Med Rehab 2017;63:104-5.

2. Gezici AR, Ergün R. Spontaneous regression of a huge subligamentous extruded disc herniation: short report of an illustrative case. Acta Neurochir (Wien) 2009;151:1299-300.

3. Macki M, Hernandez-Hermann M, Bydon M, Gokaslan A, McGovern K, Bydon A. Spontaneous regression of sequestrated lumbar disc herniations: Literature review. Clin Neurol Neurosurg 2014;120:136-41.

4. Ağırman M, Durmuş O, Saral İ, Çakar E. Resorption of extruded intervertebral disc herniation: Effect of physical therapy modalities. Turk J Phys Med Rehab 2016;62:286-7.

5. Fager CA. Observations on spontaneous recovery from intervertebral disc herniation. Surg Neurol 1994;42:282-6.

6. Senoglu M, Yuksel K, Yuksel M. Spontaneous regression of lumbar disc herniation: report of two cases. J Neurol Sci [Turk] 2006;23:4:339-43. 